\title{
Epidemiology of Grape Anthracnose: Factors Associated with Defoliation of Grape Leaves Infected by Elsinoë ampelina
}

Odile Carisse, Agriculture and Agri-Food Canada, 430 Gouin Blvd., St-Jean-sur-Richelieu, Quebec, J3B 3E6, Canada; and Vincent Morissette-Thomas, Department of Mathematics, Sherbrooke University, Sherbrooke, Quebec, Canada, J1K 2R1

\begin{abstract}
Carisse, O., and Morissette-Thomas, V. 2013. Epidemiology of grape anthracnose: Factors associated with defoliation of grape leaves infected by Elsinoë ampelina. Plant Dis. 97:222-230.

Anthracnose is a serious disease that affects several grape cultivars. Infected leaves drop prematurely, and severe epidemics result in poor or no yield. Because the factors associated with grape defoliation in vineyards with a history of anthracnose were not well known, this study was undertaken to investigate the relationship between weather-, disease-, and host-related factors and survival of leaves. From 2006 to 2008, weather, anthracnose severity, and leaf emergence were monitored in an unsprayed experimental vineyard naturally infested with Elsinoë ampelina. Each year, two to three times weekly, the number of leaves and the proportion of leaf area diseased (PLAD) were monitored on 10 vines and 2 shoots per vine, for a total of 785 leaves. Survival analysis was used to investigate the factors influencing defoliation and to model time-to-death of grape leaves. Estimated median survival time was 117 to 121 days. Based on Kaplan-Meier estimates of survival

assessment, duration and amount of rain at first infection, severity of infection and leaf age at first infection and at first severe infection significantly influenced leaf survival. Based on accelerated time failure modeling, using the Weibull distribution, the most significant variables were PLAD per leaf and PLAD per shoot at first assessment, leaf age at first infection, and duration of rain. Each additional percent increase in PLAD per leaf, in PLAD per shoot, or in rainy days accelerated the time-to-death of grape leaves by $2.84,1.02$, and $0.66 \%$, respectively, whereas for each additional day of leaf age at time of first infection, there was a $2.88 \%$ deceleration of the time to death. Results suggested that to avoid premature leaf drop, disease severity should be maintained below $25 \%$ leaf area diseased, which can be achieved by sanitation measures designed to reduce inoculum levels and by applying fungicide early in the season to prevent infection of young leaves.
\end{abstract} probabilities, season type, PLAD per leaf and PLAD per shoot at first
Grapevine anthracnose, also called grapevine black spot and bird's-eye rot, is a severe disease that affects a number of grape production areas $(5-8,13,18,21,22,32,34,35,38)$. The causal organism of grapevine anthracnose is Sphaceloma ampelinum de Bary (teleomorph Elsinoë ampelina Shear). Grapevine anthracnose can cause severe crop losses in areas with frequent rain, mainly because E. ampelina can infect all aerial parts of the vine, inducing numerous lesions on leaves, shoots, petioles, rachises, pedicels, and berries, thereby causing premature leaf and berry drop. In vineyards planted with anthracnose-susceptible cultivars, the disease is difficult to manage even with fungicide applications every 7 to 10 days $(15,17)$. In organic production, anthracnose management is especially challenging because of the lack of effective fungicides. Regardless of the type of production, conventional or organic, once the disease is established in a vineyard, yield losses and the expense of numerous fungicide applications make the production of anthracnose-susceptible grape cultivars difficult and unprofitable in warm and humid areas.

Grapevine anthracnose is considered a tropical disease $(4,5,13,20,22,32-36)$; however, outbreaks were recently reported in Quebec, Canada in vineyards planted with the cultivar VandalCliche (6-8). Evaluation of grapevine cultivar susceptibility to anthracnose showed that other winter-hardy cultivars, such as Marquette and Traminette, as well as cold-tender cultivars are susceptible to anthracnose (8). These cultivars are an important part of emerging vine production in cold climate regions, including east-

Corresponding author: Odile Carisse, E-mail: odile.carisse@agr.gc.ca

Accepted for publication 23 August 2012

http://dx.doi.org/10.1094/PDIS-04-12-0393-RE

This article is in the public domain and not copyrightable. It may be freely reprinted with customary crediting of the source. The American Phytopathological Society, 2013. ern Canada and the northeastern United States (24). Growing grapes in northern regions is challenging, mainly because of problems associated with spring frost, a short growing season, and winter vine survival. In response to these constraints, winter-hardy grape cultivars, mainly French-American hybrids, have been developed by breeders mainly in Minnesota (24). These cultivars can survive winter temperatures as low as $-37^{\circ} \mathrm{C}$ without winter protection. A key challenge for this new industry in northern climates is to find cultivars that will produce high-quality berries, economically acceptable yields, and survive winter temperatures. However, the susceptibility of winter-hardy grapevine cultivars to anthracnose (8) and the absence of proper management strategies may be a serious threat to northern viticulture.

Grape anthracnose is an emerging disease in eastern Canada and in the northeastern United States; hence, little is known about its epidemiology in northern climates. Information on the epidemiology of grape anthracnose originates primarily from studies conducted in tropical climates such as northern India, Australia, and New Zealand $(4,5,13,20,22,32-36)$. However, a recent study conducted in eastern Canada showed that the fungus overwinters as sclerotia in cane cankers formed during the previous growing season (7). In the spring, conidia are formed on these sclerotia and are released when the temperature is above $2^{\circ} \mathrm{C}$ and the sclerotia have been wetted for a minimum of $24 \mathrm{~h}(2,7,21)$. The conidia can infect young tissues at temperatures ranging from 2 to $40^{\circ} \mathrm{C}$, with the optimum temperature being around $3^{\circ} \mathrm{C}(33,35)$. Tissue surface wetness is required for infection, but there are conflicting reports on optimal duration. In 1973, Brook (4) reported that under controlled conditions, tissue wetness of 7 to $10 \mathrm{~h}, 4$ to $7 \mathrm{~h}, 2$ to $4 \mathrm{~h}$, and 1.5 to $2 \mathrm{~h}$ at temperatures of $12,16.5,21$, and $30^{\circ} \mathrm{C}$, respectively, was required for infection. In 2004, Thind et al. (35) reported that under controlled conditions, a minimum of $24,5,3$, and $4 \mathrm{~h}$ of leaf wetness was required at temperatures of $15,20,25$, and $30^{\circ} \mathrm{C}$, respectively. In 2000 , Hopkins and Harris (18) reported that in a greenhouse environment, the best conditions for infection and symptom expression were 24 to $72 \mathrm{~h}$ of wetness at temperatures 
ranging from 20 to $28^{\circ} \mathrm{C}$. At $2^{\circ} \mathrm{C}$, the symptoms are visible 14 days after infection, while at $16^{\circ} \mathrm{C}$ they are visible 4 days after infection, and new conidia are produced on lesions only a few days after they become visible (4,33). In eastern Canada, conidia are produced on cane cankers from early May to early August, which may explain the explosive nature of this disease, as the leaves are exposed to both initial and secondary inoculums for most of the season (7). Knowledge of leaf and berry age related resistance is incomplete; however, Brook (4) reported that young leaves are more susceptible to infection than fully expanded leaves. This study is part of a broader research program on grape anthracnose epidemiology and management and is aimed at identifying the factors that are related to grape defoliation in vineyards infested with $E$. ampelina.

\section{Materials and Methods}

Experimental plots. The experiment was conducted from 2006 to 2008 at the Agriculture and Agri-Food Canada experimental farm located in Frelighsburg, Quebec, Canada (lat. $45^{\circ} 03^{\prime} 12^{\prime \prime} \mathrm{N}$; long. $72^{\circ} 51^{\prime} 42^{\prime \prime} \mathrm{W}$ ) in a vineyard planted in 2000 with the grape cultivar Vandal-Cliche, which is highly susceptible to anthracnose (8). The experimental vineyard was $9 \times 36 \mathrm{~m}$ (12 rows of 48 vines). Each year, one-third of the vineyard (4 rows of 48 vines) was used for data collection and the other rows were sprayed with fungicides every 2 weeks to manage anthracnose and to avoid winter damage due to poor vine vigor and excessive primary inoculum the following spring. Each section of the vineyard was used for data collection during only 1 year. Care was taken to avoid fungicide drift to rows selected for data collection. Insecticides were applied when required mainly to control flea beetle, and all other cultural practices were carried out in accordance with standard practices used in commercial vineyards (3).

Data collection. Starting at vine growth stage 7 (first expanded leaves on Eichorh-Lorenz scale) (14,23), 10 vines were randomly selected and tagged, and each leaf present on two shoots per selected vine was assigned a unique number for tracking over time. At each assessment, new leaves, proportion of leaf area diseased, and the number of leaves defoliated were noted. The procedure was repeated two to three times weekly. Percent leaf area diseased (PLAD) was estimated using a diagrammatic scale with 5\% steps $(0,5,10,15 \ldots 100 \%)$ and expressed as proportion by dividing the percentage by 100 . The total numbers of leaves monitored were 264, 266, and 255 in 2006, 2007, and 2008, respectively. The last assessment was made on 15 October, after which disease assessment was impossible due to natural leaf senescence. A data logger (CR-10X, Campbell Scientific, Edmonton, Canada) located in the

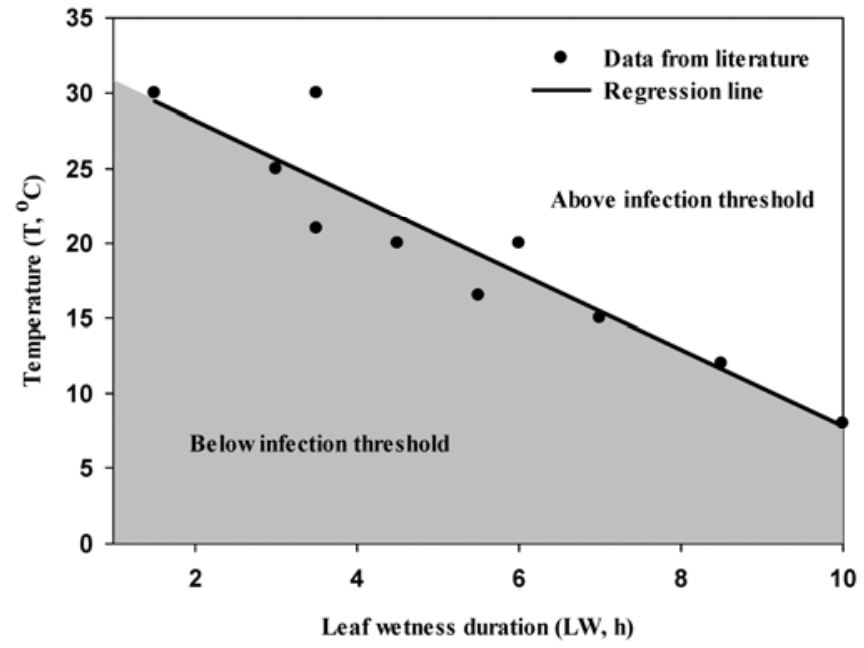

Fig. 1. Relationship between leaf wetness duration $(\mathrm{LW}, \mathrm{h})$ and temperature $\left(\mathrm{T},{ }^{\circ} \mathrm{C}\right)$ and determination of a threshold for the occurrence of infection of grape leaves by Elsinoë ampelina. The model was developed using data from the literature $(4,20,35)$ as $T=33.3476-(2.5626 \times \mathrm{LW})\left(R^{2}=0.85\right)$. center of the experimental plot was used to measure air temperature $\left({ }^{\circ} \mathrm{C}\right)$, relative humidity $(\%)$, leaf wetness duration (h), and amount of rain $(\mathrm{mm})$. The temperature and relative humidity were monitored at a height of $1.5 \mathrm{~m}$ with a Vaisala sensor (Model HMP45C, Campbell Scientific, Edmonton, Canada) located in a white shelter. Rain was monitored using a tipping bucket (Geneq, Montreal, Quebec, Canada) with the opening located $50 \mathrm{~cm}$ above the ground. Leaf wetness was monitored using two uncoated electrical grid leaf wetness sensors installed within the grapevine canopy at a height of $1.5 \mathrm{~m}$. The resistance threshold at which a leaf was considered as wet was done by wetting dry vine leaves and noting the resistance when the leaves became dry again. All data were recorded every $15 \mathrm{~min}$ and stored as hourly averages.

Calculation of weather-related variables. An infection threshold was derived from information available in the scientific literature $(4,20,35)$ (Fig. 1). Paired data of minimum duration of leaf wetness (h, LW) and temperature $\left({ }^{\circ} \mathrm{C}, \mathrm{T}\right)$ required to induce infection provided in research reports $(4,20,35)$ were modeled with linear regression as $T=\beta_{0}+\left(\beta_{1} \times \mathrm{LW}\right)$ using the GLM procedure in SAS (Statistical Analysis Program, ver. 9.2, SAS Institute, Inc., Cary, NC) (Fig. 1). The model developed by Thind et al. (34) was used to predict the severity of an infection period. Each day was divided into four 6-h periods, namely morning from 0601 to 1200 , midday from 1201 to 1800 , evening from 1801 to 2400 , and night from
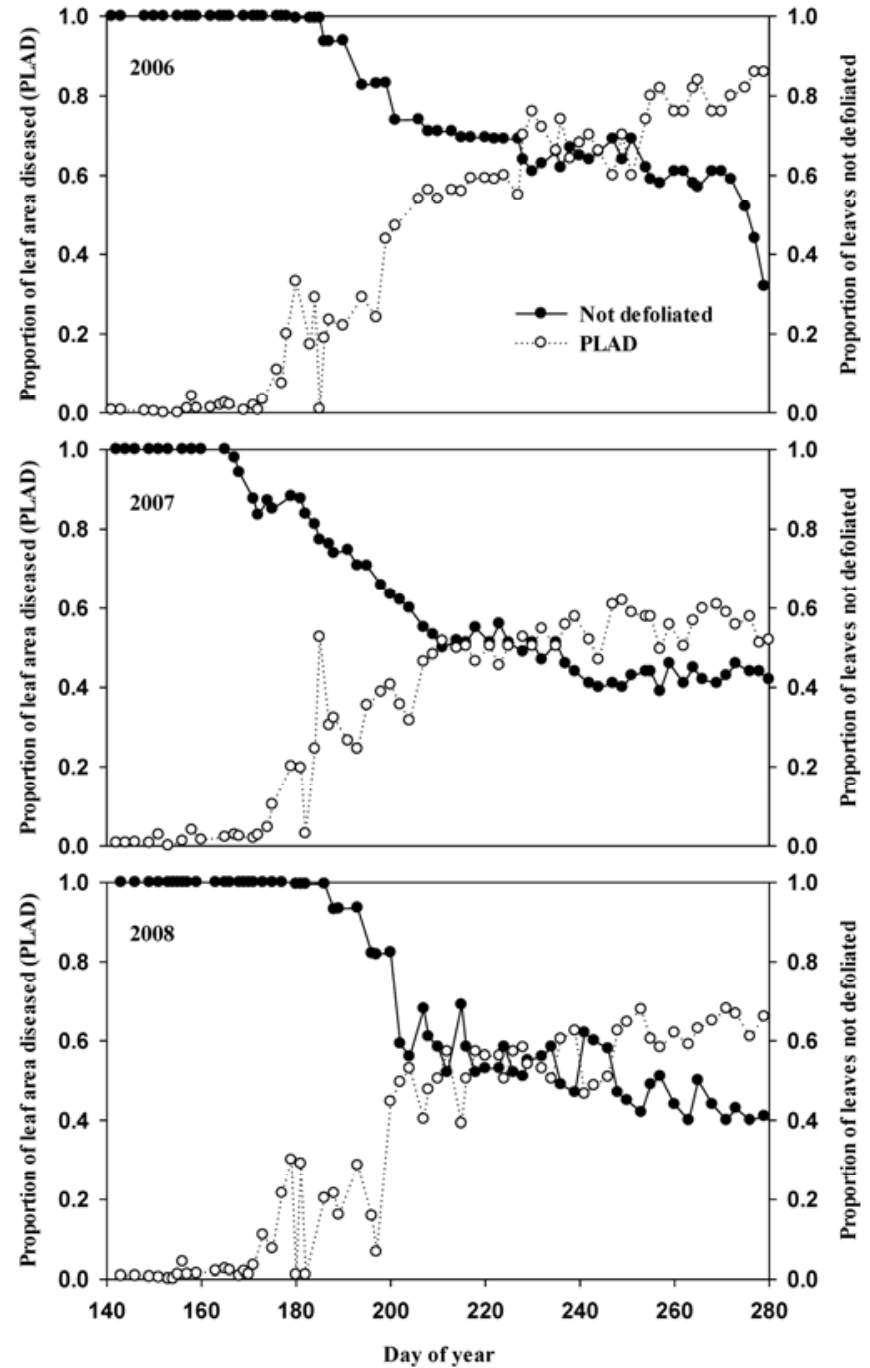

Fig. 2. Temporal progress of proportion of leaf area diseased for grape anthracnose caused by Elsinoë ampelina (empty circles) and of proportion of grape leaves not defoliated (filled circles). Data were collected from 2006 to 2008 on 785 grape leaves from an experimental vineyard (cv. Vandal Cliche) located in Frelighsburg, Quebec, Canada. 
2401 to 0600 . The following equation was used to predict grape anthracnose severity $(Y)$ on a scale of 0 to $100 \%$ (34):

$Y=-51.0158-\left(0.0989 \times T_{\max }\right)+\left(8.466 \times T_{\min }\right)-\left(6.452 \times T_{\text {mean }}\right)+(1.88 \times$ $\left.\mathrm{RH}_{\text {mor }}\right)-\left(0.830 \times \mathrm{RH}_{\text {eve }}\right)-\left(0.0257 \times \mathrm{Rh}_{\mathrm{m}}\right)+(0.0465 \times$ Rain $)$

where $T_{\max }, T_{\min }$, and $T_{\text {mean }}$ are daily maximum, minimum, and mean temperature $\left({ }^{\circ} \mathrm{C}\right)$, respectively; $\mathrm{RH}_{\text {mor }}, \mathrm{RH}_{\text {eve }}, \mathrm{Rh}_{\mathrm{m}}$ are daily morning, evening, and mean relative humidity (\%), respectively; and Rain is the daily amount of rain ( $\mathrm{mm}$ ).

Data analysis. The weather-, disease-, and host-related variables for the 3 years were transformed into categorical variables as follows: (i) season type, as SEASON with $>700 \mathrm{~mm}$ rain or with $<700 \mathrm{~mm}$ of rain during the grape growing season (based on 30year averages of $694 \mathrm{~mm}$ of rain from 15 April to 15 October), respectively; (ii) amount of rain when the leaf was first infected, as RAIN $<10 \mathrm{~mm}, 10-30 \mathrm{~mm}$, or $>30 \mathrm{~mm}$ of rain; (iii) number of consecutive rainy days ( $>10 \mathrm{~mm}$ of rain daily) when the leaf was first infected, as $\operatorname{RAIN}_{\text {dur }}=1,2,3$, or $>3$ days, respectively; (iv) the predicted severity of infection from equation 1 , as PSEV $<25 \%$, 25 to $49 \%$, or $\geq 50 \%$; (v) percent leaf area diseased ( $\mathrm{PLAD}_{\text {leaf }}$ ) at first assessment, as PLAD < 10\%, 10 to $24 \%, 25$ to $50 \%,>50 \%$;

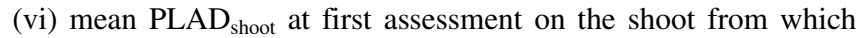
the leaf originated, as $\mathrm{PLAD}_{\text {shoot }}<10 \%, 10 \% \geq \mathrm{PLAD}_{\text {shoot }}<25 \%$, $25 \% \geq \mathrm{PLAD}_{\text {shoot }}<50 \%$, or PLAD $\mathrm{Phoot}_{\text {sho }} \geq 50 \%$; (vii) leaf age at time of first infection (above threshold, Fig. 1), as $\mathrm{LAGE}_{\mathrm{I}}=1$ to 2,3 to 4,5 to 6 , or $>6$ days; and (viii) leaf age at time of first severe infec- tion (PSEV $\geq 50 \%$ ), as $\mathrm{LAGE}_{\mathrm{SI}}=<5,5$ to 9,10 to 15 , or $>15$ days, respectively. The equality of the mean grape leaf survival time (in days) for the different categories of variables was compared with the non-parametric Kruskal-Wallis ANOVA test at the 0.05 confidence level (30).

Survival analysis. Because the data included several right censored observations (leaves that had not defoliated within the period of the study) and because time to defoliation is a "survival time," survival analysis was used to describe and model the grape leaf survival data $(1,9-12,16,19,27)$. Survival analysis was conducted following four steps, and all analyses were carried out with the SAS Statistical Analysis Program ver. 9.2 (SAS Institute).

First, independence of observations made on the same plant and on the same shoot was tested. One of the assumptions underlying survival analysis is the independence of the data; however, in this study observations were made on leaves collected on the same plant and on the same shoot; hence independence of observations was a concern. The autocorrelations between observations made on the same plant and on the same shoot were tested with the ARIMA procedure in SAS. Since only one of the 30 plants and four of the 60 shoots showed significant $(P<0.05)$ autocorrelation patterns, we considered that observations from different leaves on the same plant and on the same shoot were independent.

The second step involved descriptive analysis using the life table method (16). From this analysis, it was possible to derive statistics (median survival time, survivor function, and hazard function)
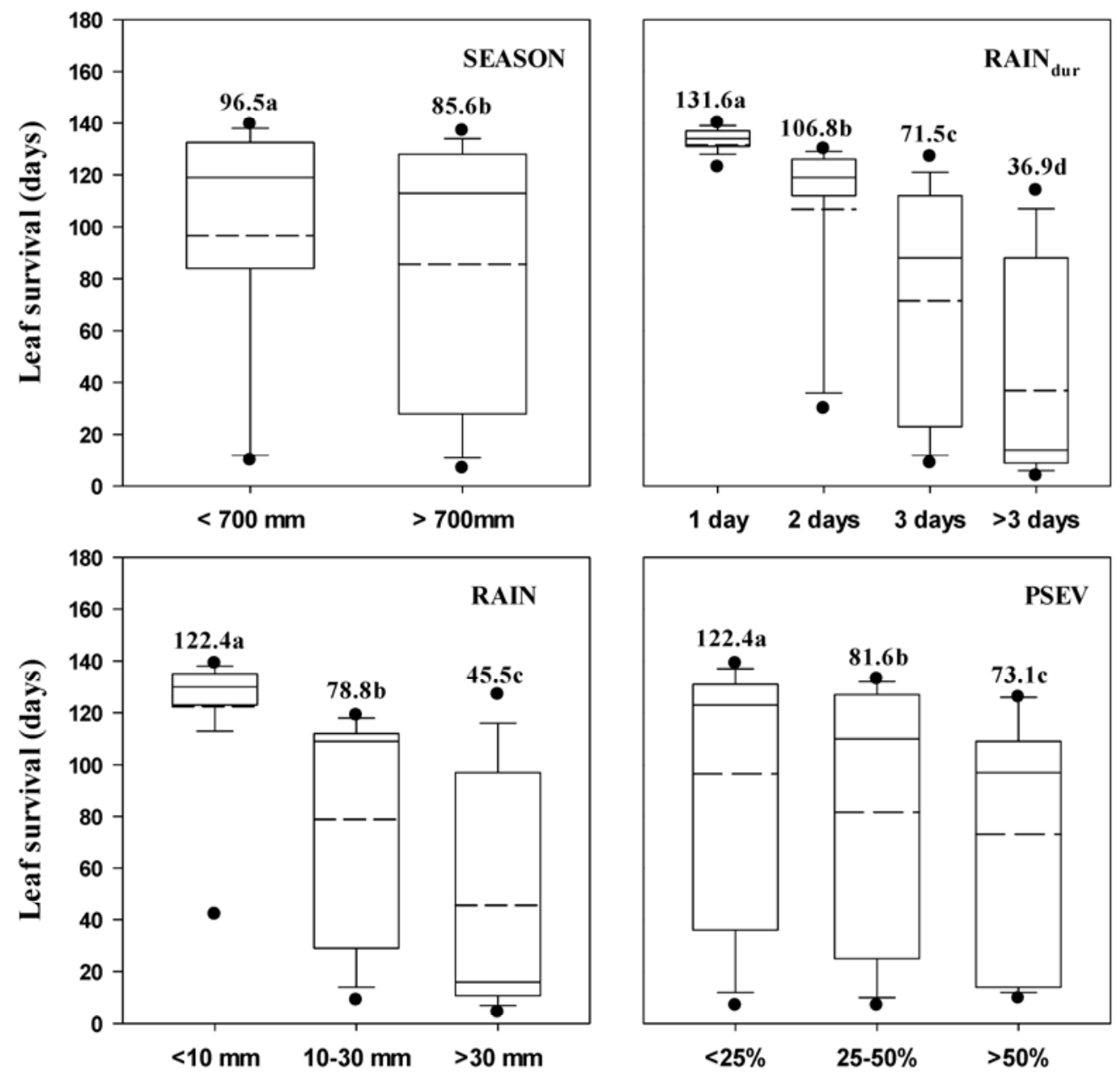

Weather-related variables

Weather-related variables

Fig. 3. Distribution of grape leaf survival based on weather-related variables. Leaves $(n=785)$ were collected from 2006 to 2008 in an experimental vineyard (cv. Vandal Cliche) located in Frelighsburg, Quebec, Canada naturally infested by grape anthracnose caused by Elsinoë ampelina. Boxes represent the interquartile range, whiskers indicate the 5- and 95-percentiles, and lines within the boxes represent median (filled line) and mean (dashed line) survival time. Values are mean survival time in days and values with the same letter are not significantly different based on a Kruskal-Wallis ANOVA at the 0.05 level of confidence. 
which were used to describe grape leaves survival. The median survival time or life expectancy was defined as the amount of time that $50 \%$ of the individuals in the study are expected to survive (1). The survivor function, $S(t)$, is a cumulative distribution function describing the probability that a leaf present at time 0 will survive until time $t$. It is defined as $S(t)=\operatorname{Pr}(T \geq t)$, where $T$ is the time to leaf death for each individual leaf. The hazard function, $h(t)$, is the conditional probability density function describing the immediate risk that leaf death will occur at time $t$, given that it has not occurred before, and is calculated as $(1,16,19)$ :

$h(t)=\lim _{\Delta t \rightarrow 0} \frac{\operatorname{Pr}[(t \leq T<t+\Delta t) \mid T \geq t]}{\Delta t}$

Because we were interested in investigating the influence of weather-, disease-, and host-related variables on survival of grape leaves infected with E. ampelina, the third step consisted in using survivor functions to compare groups of leaves based on the Kaplan-Meier estimates of survival probabilities using the log-rank test $(1,16,19)$. The concept here is that if the survivor function for one group is higher than the survivor function for another group, then the leaves from the first group will survive longer than those from the second group. The Kaplan-Meier estimator defines the proportion of grape leaves surviving to a specific time $(t)$ and was calculated as follows:
$\hat{S}(t)=\prod_{j=1}^{k}\left(\frac{n_{j}-d_{j}}{n_{j}}\right)$

where $n_{j}$ is the number of living grape leaves just prior to time $t_{j}$, and $d_{j}$ is the number of dead leaves at time $t_{j}$, where $t_{k} \leq t \leq t_{(k+1)}$ for $k=1,2,3 \ldots r$, where $r$ the number of event times (sampling events) $(1,16,19)$.

The fourth step consisted in modeling the time-to-death of grape leaves infected with E. ampelina. To model the relationship between time-to-death of grape leaves and covariates related to weather, disease severity, and host expressed as continuous variables, two types of regression models were used: Cox proportional hazard (PH) and the accelerated failure time (AFT). In the Cox proportional hazard model, the hazard at time $t$ is the probability that a leaf which has survived to time $t$ will die in the next short period of time $(1,9,11,12)$. With the Cox proportional hazard model, there is no need to know the probability distribution representing survival time. However, one of the assumptions underlying the $\mathrm{PH}$ approach is proportionality, that is, for a given covariate, the hazard functions at different levels of that covariate are proportional (hazard functions are similar). The general form for the Cox proportional hazard model is:

$h\left(t, x_{i}\right)=e^{f\left(x_{i}\right)} h_{0}(t)$
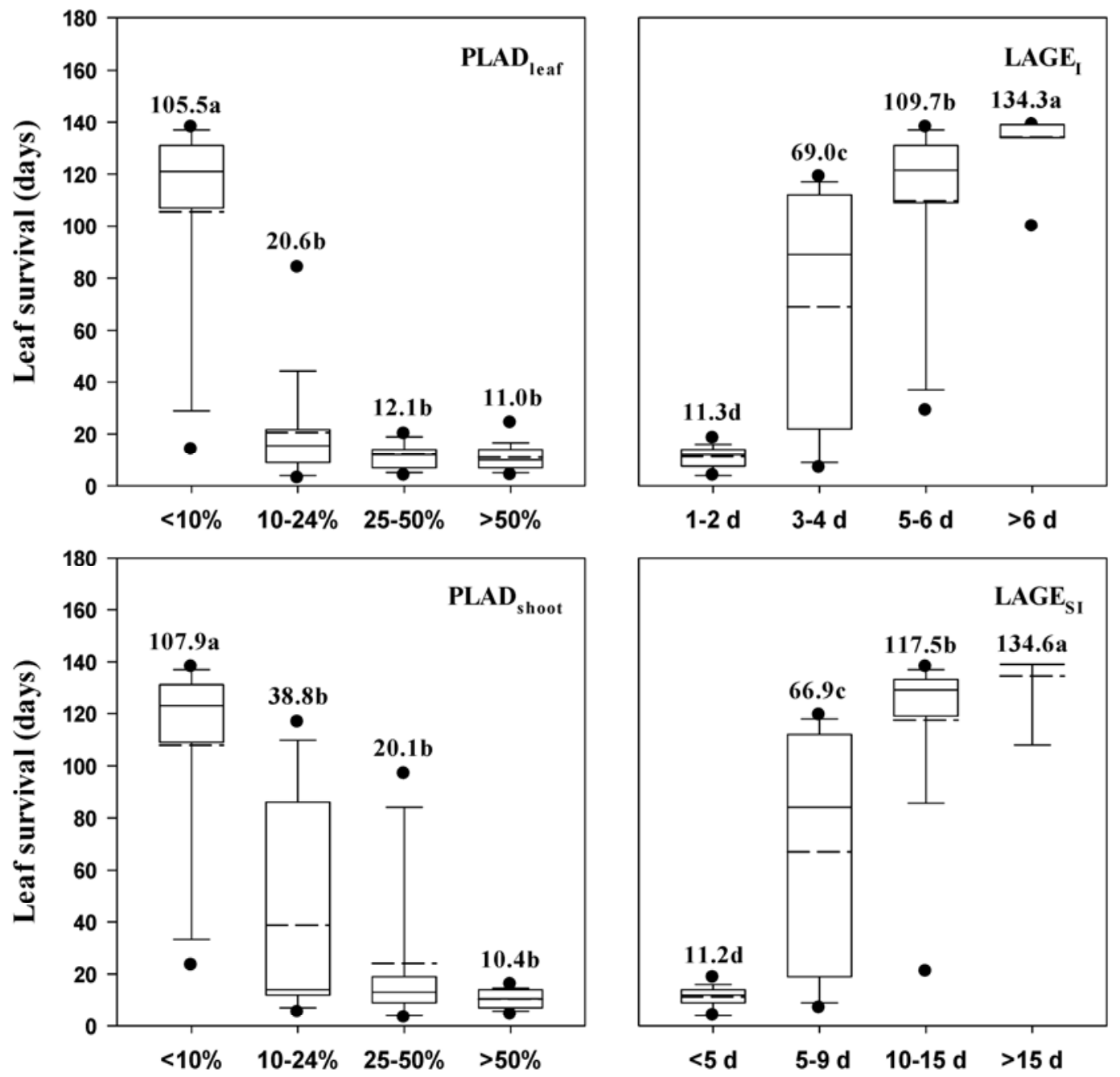

Disease-related variables

Host-related variables

Fig. 4. Distribution of grape leaf survival based on disease- and host-related variables. Leaves $(n=785)$ were collected from 2006 to 2008 in an experimental vineyard (cv. Vandal-Cliche) located in Frelighsburg, Quebec, Canada naturally infested with grape anthracnose caused by Elsinoë ampelina. Boxes represent the interquartile range, whiskers indicate the 5- and 95-percentiles, and lines within the boxes represent median (filled line) and mean (dashed line) survival time. Values are mean survival time in days and values with the same letter are not significantly different based on a Kruskal-Wallis ANOVA at the 0.05 level of confidence. 
where $e^{f\left(x_{i}\right)}$ represents how the covariates influence leaf survival by comparing the hazard to the baseline, and $h_{0}(t)$ is an arbitrary baseline hazard function that is assumed to be the same for all groups $(1,9,11,12)$. To build the model, a backward approach was used: first all the variables were included in the model. Because the number of variables was small and because we did not have any prior knowledge of specific interactions, all the possible interactions were considered. To test the assumption of proportionality, time-dependent covariates were added to the model as interactions of all covariates with log (time) using the TEST statement in SAS. The analysis was conducted using the PHREG procedure in SAS. The likelihood ratio test was used to compare the different models to the null model and a $\chi^{2}$ test was used to determine if models with additional covariates significantly improved the null model $(10,19)$.

The general form of the accelerated failure time model is:

$\log t_{i}=f\left(x_{i}\right)+\varepsilon_{i}$

where $f\left(x_{i}\right)$ expresses how the covariates influence the log of timeto-death and $\varepsilon_{i}$ is the error distribution $(1,19)$. Data for the 3 years were pooled and all covariates were included in the model except the SEASON variable, and six distributions (Weibull, exponential, log-logistic, lognormal, logistic, and normal) were tested using the LIFEREG procedure in SAS. The distributions were evaluated based on statistical convergence of estimated parameters in the model and on the log-likelihood values, from which the Akaike information criterion (AIC) was calculated, with smaller values indicating a better fit (31). Once a distribution was selected, the best model was determined by including the covariates one at a time. The best model was selected based on a likelihood test used to compare the different models to the null model, and a $\chi^{2}$ test was used to determine if the models with additional covariates improved the null model (31).

\section{Results}

The three seasons (15 April to 15 October) targeted by the study were characterized by similar mean air temperature above the grape canopy of $15.5,15.1$, and $16.9^{\circ} \mathrm{C}$ in 2006,2007 , and 2008 , respectively. Similarly, there were 69,68 , and 60 days with more than $1 \mathrm{~mm}$ of rain in 2006, 2007, and 2008, respectively. The amount of rain differed between seasons with 921, 658, and 645 $\mathrm{mm}$ in 2006, 2007, and 2008, respectively. For the three seasons, anthracnose severity remained low until the mid-June (around day 170) period, during which no defoliation was observed (Fig. 2). After this point, as the proportion of diseased leaf area increased, defoliation increased (Fig. 2). Proportion of diseased leaf area at the end of the season was $0.86,0.52$, and 0.63 , in 2006, 2007, and 2008, respectively (Fig. 2). The proportion of leaves not defoliated at the end of the season was $0.32,0.42$, and 0.39 in 2006, 2007, and 2008, respectively (Fig. 2).

Based on the Kruskal-Wallis ANOVA test, there were significant differences in mean leaf survival between season $(P=0.002)$ as well as between the different rain intensities $(P<0.0001)$ and durations $(P<0.0001)$ and between predicted disease severity groups $(P<0.0001)$ (Fig. 3). For the disease-related variables, there was a significant difference in mean leaf survival between
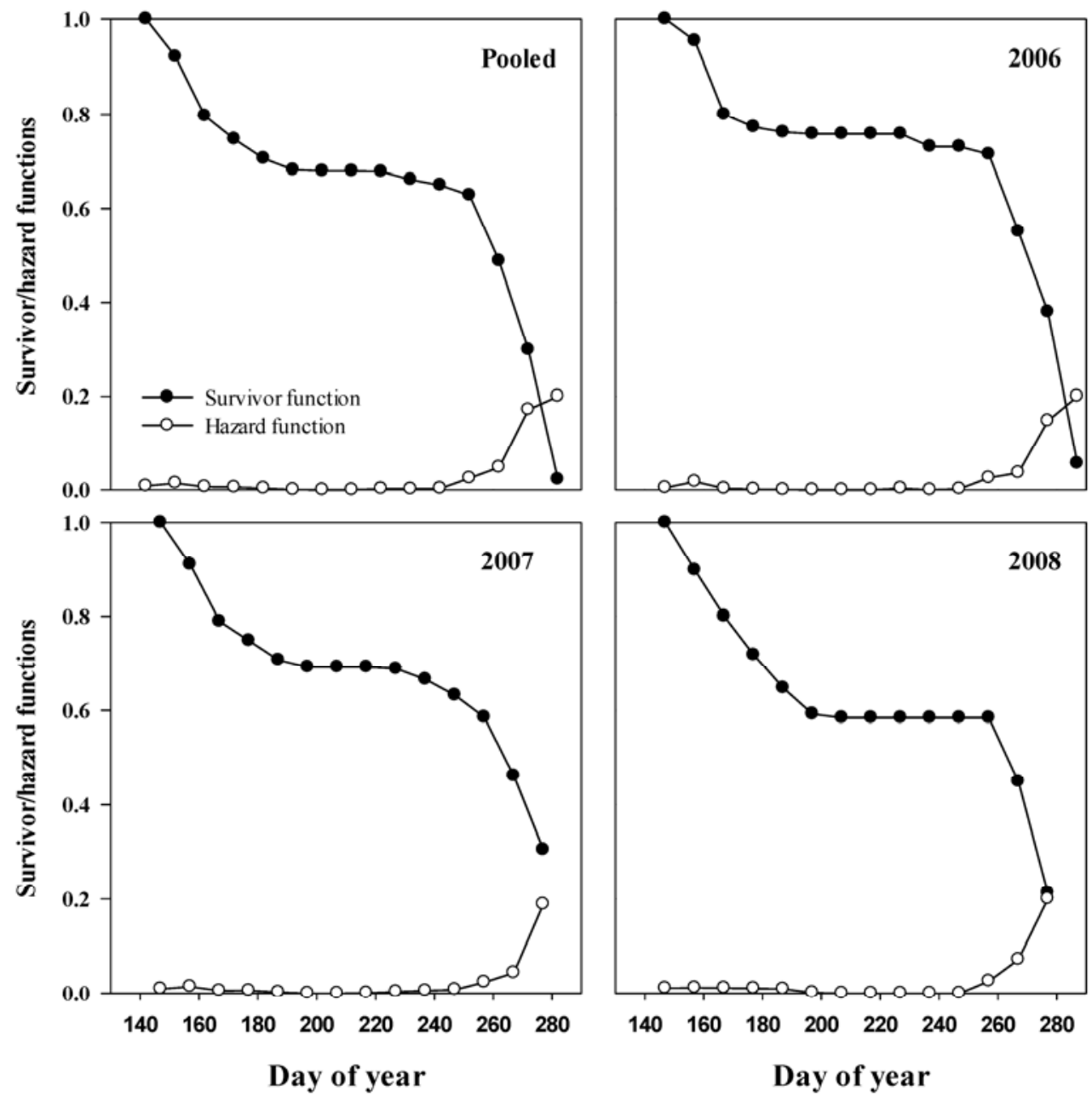

Fig. 5. Life-table estimates of the survivor (filled circles) and hazard (empty circles) functions describing defoliation of individual grape leaves in an experimental vineyard (cv. Vandal-Cliche) located in Frelighsburg, Quebec, Canada. Functions are presented for the pooled data $(n=785)$ and data collected in $2006(n=264), 2007(n=266)$, and $2008(n=255)$. 
groups of leaves with $\mathrm{PLAD}_{\text {leaf }}<10 \%$ and $\mathrm{PLAD}_{\text {leaf }} \geq 10 \%$ and between groups of leaves with $\mathrm{PLAD}_{\text {shoot }}<10 \%$ and $\mathrm{PLAD}_{\text {shoot }} \geq$ $10 \%$ at the time of the first assessment $(P<0.0001)$ (Fig. 4). The mean leaf survival was significantly $(P<0.0001)$ influenced by the age of the leaf at the time of the first infection, $\mathrm{LAGE}_{\mathrm{I}}$, or at the time of the first severe infection, LAGE $_{\mathrm{SI}}$ (Fig. 4).

Of the 785 leaves under study, 71 leaves did not die within the time frame of the study, representing $9.04 \%$ censored data. Overall, leaf survival was similar for the three seasons, with a mean leaf survival of $83.61 \pm 3.28$ days (median of 117 days), $90.55 \pm 3.09$ days (median of 118 days), and $98.91 \pm 3.03$ days (median of 121 days) in 2006, 2007, and 2008, respectively. The hazard function indicates that the instantaneous risk of defoliation was low early in the season, then remained constant from day 182 to about day 250, after which it increased rapidly until the end of the experiment (Fig. 5).

The difference in survival time for season types was small but significant with a 0.64 and 0.74 probability of leaf survival for 50 days for seasons with $>700$ and $<700 \mathrm{~mm}$ rain, respectively (Table 1; Fig. 6). Similarly, the difference in survival time for the different levels of weather-based predicted anthracnose severity (PSEV) was significant, but the difference was small for PSEV $=25$ to $50 \%$ and PSEV $>50 \%$, with a probability of leaf survival for 50 days of 0.61 and 0.60 for PSEV $=25-50 \%$ and PSEV $>50$, respectively, while the probability was 0.73 when PSEV $<25 \%$ (Table 1 ; Fig. $6)$. For both the duration of infection periods in days $\left(\operatorname{RAIN}_{\text {dur }}\right)$ and amount of rain in $\mathrm{mm}\left(\mathrm{RAIN}_{\mathrm{int}}\right)$, the differences in survival time among groups were significant $(P<0.001)$ (Table 1$)$. The probability of leaf survival for 50 days was $0.97,0.82,0.56$, and 0.27 for RAIN $_{\text {dur }}$ of 1, 2, 3, and $>3$ days, respectively (Fig. 6). Similarly, the probability of leaf survival for 50 days was $0.92,0.65$, and 0.32 for RAIN $<10 \mathrm{~mm}, 10$ to $60 \mathrm{~mm}$, and $>30 \mathrm{~mm}$, respectively (Fig. 6). For the two disease-related variables, PLAD leaf $_{\text {and }}$ PLAD shoot $_{\text {, }}$ the differences in survival time among groups were significant $(P<$ 0.001 ) (Table 1). The probability of leaf survival for 25 days was $0.92,0.15,0.01$, and 0.00 for $\mathrm{PLAD}_{\text {leaf }}$ of $<10 \%, 10$ to $25 \%, 26$ to $50 \%$, and $>50 \%$, respectively (Fig. 7). Similarly, the probability of a leaf survival for 25 days was 0.94 when PLAD shoot $_{\text {was }}<10 \%$ and then dropped to $0.32,0.15$, and 0.00 when PLAD shoot was 10 to $25 \%, 26$ to $50 \%$, and $>50 \%$, respectively (Fig. 7). For the hostrelated variables, leaf age at the first infection $\left(\mathrm{LAGE}_{\mathrm{I}}\right)$ and leaf age at the first severe infection $\left(\mathrm{LAGE}_{\mathrm{SI}}\right)$, the difference in survival time was significant (Table 1). The probability of leaf survival for 25 days was $0.00,0.73,0.98$, and 1.00 for $\mathrm{LAGE}_{\mathrm{I}}$ of $<2,3$ to 4,5 to 6 , and $>6$ days, respectively (Fig. 7 ). Similarly, the probability of leaf survival for 25 days was $0.00,0.70,0.94$, and 1.00 for LAGE $_{\mathrm{SI}}$ of $<5,5$ to 9,10 to 15 , and $>15$ days, respectively (Fig. 7).

Because the time-dependent variables were significant individually, we considered that the assumption of proportionality was not satisfied for the Cox proportional hazard model; hence the time-todeath of grape leaves was modeled using the accelerated failure time (AFT) model. Based on the log-likelihoods and Akaike information criterion (AIC) for the full model, the best model was the Gamma model; however, this model was not selected because of the questionable convergence of parameter estimates (Table 2). The Weibull model was therefore used to study the influence of the different covariates. The best model included the covariates $\mathrm{PLAD}_{\text {leaf }}, \mathrm{PLAD}_{\text {shoot}}, \mathrm{LAGE}_{\mathrm{I}}$, and RAIN $\mathrm{Rur}_{\text {dur }}$, indicating that these variables significantly influenced the survival of grape leaves. The best AFT model describing the time-to-death of grape leaves infected with $E$. ampelina was:

$\log t_{i}=4.7864-0.0288 \times\left(\mathrm{PLAD}_{\text {leaf }}\right)-0.0103 \times\left(\mathrm{PLAD}_{\text {shoot }}\right)+0.0284$ $\times\left(\mathrm{LAGE}_{\mathrm{I}}\right)-0.0066 \times\left(\mathrm{RAIN}_{\mathrm{dur}}\right)+\varepsilon_{i}$

where $\log t_{i}$ is the $\log$ of time-to-death and $\varepsilon_{i}$ is the error distribution term. The parameter estimates $(\beta)$ for $\operatorname{PLAD}_{\text {leaf }}$, PLAD $\mathrm{D}_{\text {shoot }}$,

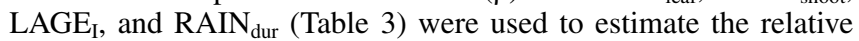
change in survival time for each additional unit of the covariates as: $100 \% \times\left(e^{\beta}-1\right)(19)$. Based on the parameter estimate for $\operatorname{PLAD}_{\text {leaf }}\left(\beta_{1}=-0.0288\right)$, each additional percent of leaf area dis- eased $\left(\mathrm{PLAD}_{\text {leaf }}\right)$ at the first assessment accelerated the time-todeath of grape leaves by $2.84 \%$. For PLAD $\operatorname{Psoot}_{\text {sho }}\left(\beta_{2}=-0.0103\right)$, each additional percent in mean percent leaf area diseased at first assessment on the shoot from which the leaf originated accelerated the time-to-death of grape leaves by $1.02 \%$. Similarly, for RAIN ${ }_{\text {dur }}$ $\left(\beta_{4}=-0.0066\right)$, each additional day of rain accelerated the time-todeath of grape leaves by $0.66 \%$. For leaf age $\left(\mathrm{LAGE}_{\mathrm{I}}\right)\left(\beta_{3}=\right.$ 0.0284 ), when leaves were 1 day older, the time-to-death of grape leaves decelerated by $2.88 \%$.

\section{Discussion}

Because of the dearth of knowledge on grape anthracnose epidemiology, especially in northern climates, it is difficult to design efficient management strategies. Consequently, the primary management schemes consist mostly in applying fungicides weekly or biweekly depending on cultivar susceptibility, history of anthracnose, and frequency of rain. Another factor that makes grape anthracnose management difficult is its capacity to induce defoliation within a short period of time (a few weeks). The observations made during this study on the severity of grape anthracnose support other reports on the capacity of E. ampelina to seriously damage grapevines with a maximum percent leaf area diseased of $86 \%$ and a maximum percent leaf defoliation of 68\% recorded in 2006 (Fig. 2 ). There are relatively few reports on the influence of diseaseinduced premature defoliation and yield $(28,37)$. The relationship between defoliation induced by grape anthracnose and yield, plant vigor, or winter survival has not been studied. However, leaf removal in the fruiting zone during the summer season is a common cultural practice in several grape producing areas (25). Leaf removal is used as a tool to increase air circulation around the clusters, reducing the incidence of the bunch rot complex of diseases

Table 1. Median survival time and log rank statistics for groups of grape leaves of cv. Vandal-Cliche monitored in 2006 to 2008 in Frelighsburg, Quebec, Canada

\begin{tabular}{|c|c|c|c|c|}
\hline Variable & $\begin{array}{c}\text { Median } \\
\text { (days) }\end{array}$ & $\begin{array}{l}\text { Standard } \\
\text { error }\end{array}$ & df & $\begin{array}{c}\log \text { rank test } \\
\text { statistic }(P \text { value })\end{array}$ \\
\hline \multicolumn{3}{|l|}{ SEASON } & \multirow[t]{3}{*}{1} & \multirow[t]{3}{*}{$15.252(<0.001)$} \\
\hline$<700 \mathrm{~mm}$ & 121 & 1.78 & & \\
\hline$>700 \mathrm{~mm}$ & 118 & 1.70 & & \\
\hline \multicolumn{3}{|l|}{$\mathrm{RAIN}_{\text {dur }}$} & \multirow[t]{5}{*}{3} & \multirow{5}{*}{$710.417(<0.001)$} \\
\hline 1 day & 134 & 0.54 & & \\
\hline 2 days & 120 & 0.66 & & \\
\hline 3 days & 109 & 1.15 & & \\
\hline$>3$ days & 14 & 0.24 & & \\
\hline \multicolumn{3}{|l|}{ RAIN } & \multirow[t]{4}{*}{2} & \multirow{4}{*}{$494.720(<0.001)$} \\
\hline$<10 \mathrm{~mm}$ & 130 & 0.40 & & \\
\hline $10-30 \mathrm{~mm}$ & 110 & 0.64 & & \\
\hline$>30 \mathrm{~mm}$ & 16 & 1.17 & & \\
\hline \multicolumn{3}{|l|}{ PSEV } & \multirow[t]{4}{*}{2} & \multirow[t]{4}{*}{$61.377(<0.001)$} \\
\hline$<25 \%$ & 125 & 1.39 & & \\
\hline $25-50 \%$ & 111 & 2.69 & & \\
\hline$>50 \%$ & 107 & 10.64 & & \\
\hline \multicolumn{3}{|l|}{ PLAD } & \multirow[t]{5}{*}{3} & \multirow[t]{5}{*}{$848.757(<0.001)$} \\
\hline$<10 \%$ & 125 & 0.76 & & \\
\hline $10-24 \%$ & 16 & 0.92 & & \\
\hline $25-50 \%$ & 12 & 0.57 & & \\
\hline$>50 \%$ & 10 & 2.39 & & \\
\hline \multicolumn{3}{|l|}{ PLAD $_{\text {shoot }}$} & \multirow[t]{5}{*}{3} & \multirow{5}{*}{$670.173(<0.001)$} \\
\hline$<10 \%$ & 126 & 0.55 & & \\
\hline $10-24 \%$ & 14 & 1.01 & & \\
\hline $25-50 \%$ & 13 & 0.68 & & \\
\hline$>50 \%$ & 9 & 1.27 & & \\
\hline \multicolumn{5}{|l|}{$\mathrm{LAGE}_{\mathrm{I}}$} \\
\hline 1-2 days & 12 & 0.652 & \multirow[t]{4}{*}{3} & \multirow[t]{4}{*}{$978.734(<0.001)$} \\
\hline 3-4 days & 93 & 13.503 & & \\
\hline 5-6 days & 130 & 0.316 & & \\
\hline$>7$ days & 134 & 6.191 & & \\
\hline \multicolumn{3}{|l|}{$\mathrm{LAGE}_{\mathrm{SI}}$} & \multirow[t]{5}{*}{3} & \multirow{5}{*}{$770.856(<0.001)$} \\
\hline$<5$ days & 12 & 0.721 & & \\
\hline 5-9 days & 86 & 15.454 & & \\
\hline $10-15$ days & 129 & 0.453 & & \\
\hline$>15$ days & 139 & 0.001 & & \\
\hline
\end{tabular}



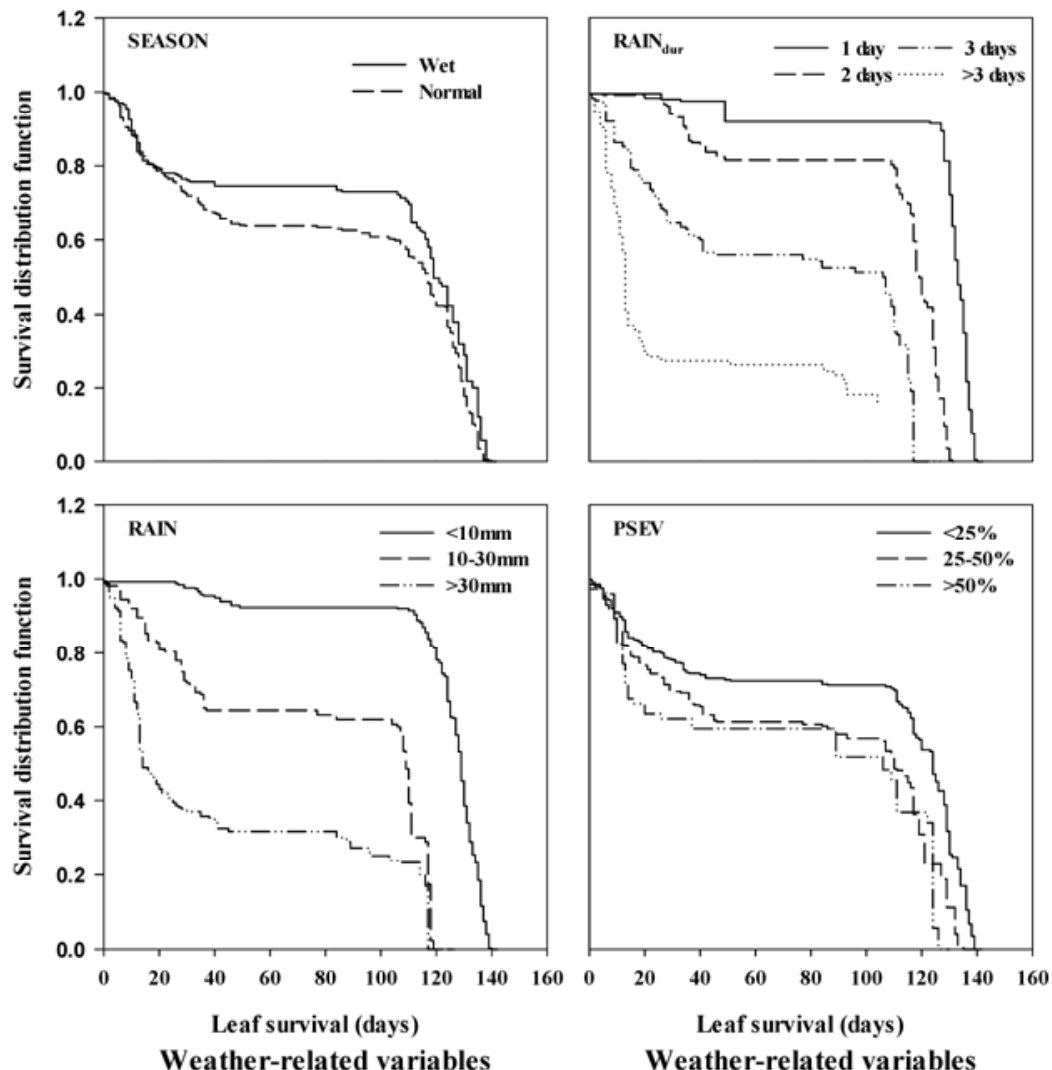

Weather-related variables

Fig. 6. Kaplan-Meier estimates of survival functions describing time-to-defoliation of individual grape leaves $(n=785)$ in an experimental vineyard (cv. Vandal-Cliche) located in Frelighsburg, Quebec, Canada. Leaves were classified according to season types (SEASON), rain duration (RAIN dur) and amount of rain (RAIN), and weather-based predicted (Eq. 1) severity of anthracnose (PSEV).
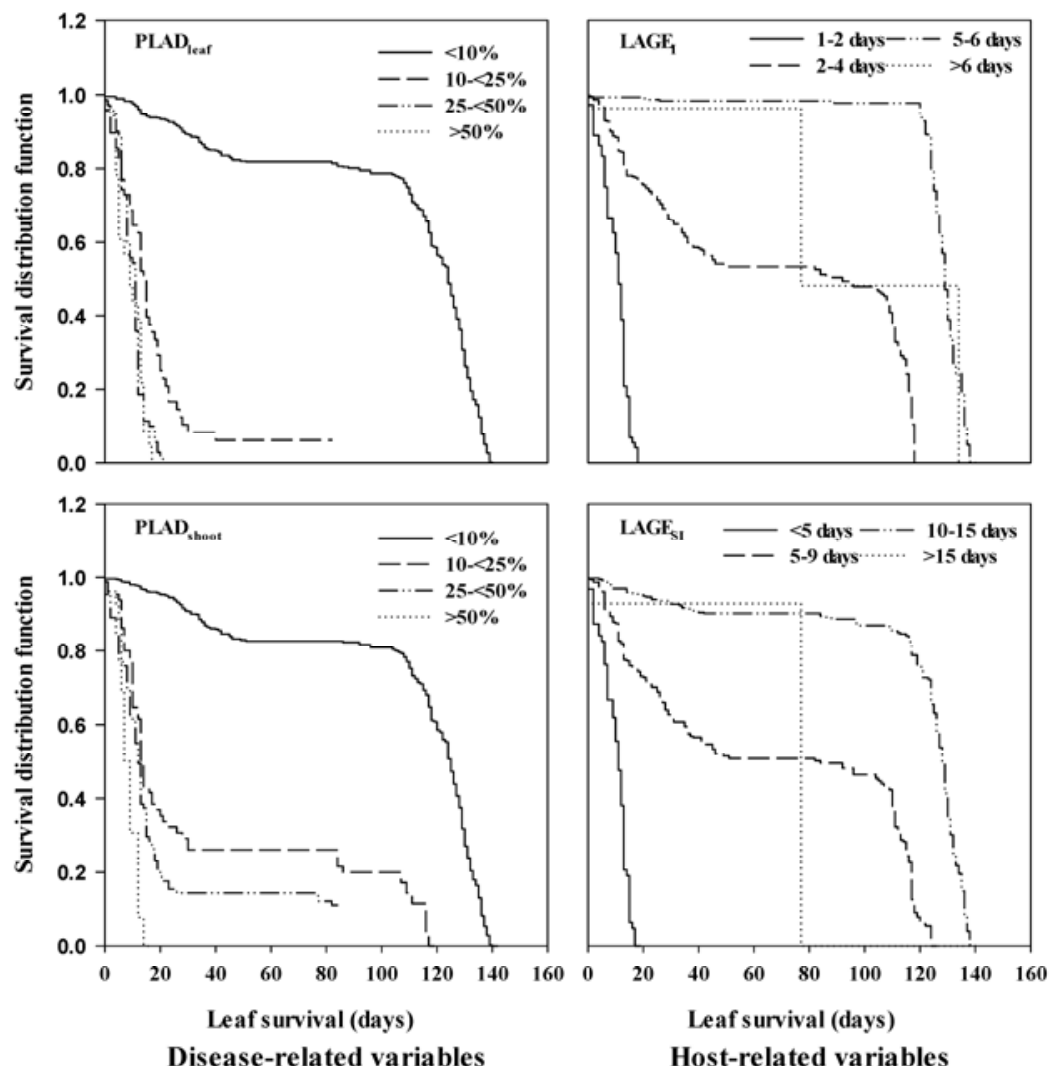

Fig. 7. Kaplan-Meier estimates of survival functions describing time-to-defoliation of individual grape leaves $(n=785)$ in an experimental vineyard (cv. Vandal-Cliche) located in Frelighsburg, Quebec, Canada. Leaves were classified according to proportion of leaf area diseased at first infection ( $P L A D_{\text {leaf }}$ ) and mean proportion of leaf area diseased at first infection on the shoot where the leaf originated $\left(P L A D_{\text {shoot }}\right)$, leaf age at first infection $\left(L A G E_{1}\right)$, and leaf age at first severe infection (LAGE $\left.{ }_{S I}\right)$. 
and facilitating fungicide penetration into the canopy. However, leaf removal can be detrimental to fruit quality because of excessively high light intensity and temperature. In some red cultivars, excessive leaf removal can lead to reduced berry color. In addition, Sabbatini and Howell (26) conducted an experiment to determine whether early leaf removal influences vine productivity. For most cultivars included in their study, removal of four or six basal leaves resulted in an average fruit set reduction of $45 \%$ compared with a control (no leaf removal). In addition, their results showed a carryover effect of leaf removal the following year with a reduced number of clusters per shoot and reduced fruit set and yield per vine. In the absence of a leaf removal or defoliation tolerance level and considering that E. ampelina can significantly reduce the healthy leaf area, it is probably better to avoid defoliation induced by E. ampelina. Moreover, considering that young leaves are more susceptible to E. ampelina than old ones (4), if the pathogen is abundant early in the season when young leaves are present and the conditions favorable, it will cause shoot tip dieback, potentially affecting fruit set and berry quality (4). If the disease occurs later in the season, it will not affect the old leaves present in the fruiting zone (33), and will therefore not provide improved air circulation around the fruit zone.

Knowledge of the dynamics of grape leaf defoliation induced by E. ampelina is therefore crucial to anthracnose management. In this study, the survival of 785 leaves was studied during three growing seasons in a vineyard planted with the highly susceptible cultivar Vandal-Cliche (8). The survival data include censored data; thus, conventional methods such as ordinary least square regression analysis cannot be used to identify the most influential variables. Because these methods cannot handle censored data, these data are often eliminated, generating a loss of information. In addition, survival analysis is the only method that can accommodate time-dependent variables. For example, when studying diseaseinduced defoliation, it is generally of interest to study the influence of disease severity on leaf survival. Such information could be used to derive the severity threshold above which the risk of defoliation is high. However, disease severity is most often time-dependent because if no control measures are applied, severity is expected to change during the course of the study.

For the 3 years of this study, defoliation remained low until about mid-June, after which defoliation increased rapidly. As well, the median grape leaf survival was 117,118 , and 121 days in 2006, 2007, and 2008, respectively. Based on the Kaplan-Meier esti-

Table 2. Log-likelihood and Akaike information criterion (AIC) used to determine distributions that best describe survival of grape leaves infected with Elsinoë ampelina from 2006 to 2008 in Frelighsburg, Quebec, Canada

\begin{tabular}{lcc}
\hline Distribution $^{\mathbf{y}}$ & Log-likelihood & AIC $^{\mathbf{z}}$ \\
\hline Lognormal & -774.355 & $1,566.711$ \\
Gamma & -541.586 & $1,103.172$ \\
Exponential & -926.150 & $1,868.301$ \\
Weibull & -712.166 & $1,442.333$ \\
Log-logistic & -743.723 & $1,505.526$ \\
Logistic & $-3,532.245$ & $7,082.490$ \\
Normal & $-3,554.639$ & $7,082.490$ \\
\hline
\end{tabular}

y Best distribution was selected based on smallest AIC value and statistical convergence of estimated parameters in the model.

${ }^{\mathrm{z}} \mathrm{AIC}=-2(\log$-likelihood $)+2 \times k$, where $k=$ penalty for extra parameters. mates, there were significant differences among groups of leaves for all weather-, disease-, and host-related variables tested. However, based on the accelerated failure time model with a Weibull distribution, the most influential variables were the percent leaf area diseased at the time of the first infection, the mean percent leaf area diseased per shoot at the time of the first infection, the rain duration, and the age of leaves at the time of the first infection. Because of the difficulty in estimating the amount of inoculum available during each infection due to the very small spore size (1 $\times 2 \mu \mathrm{m})(23,29)$, in this study the percent leaf area diseased at the time of infection could be used as a variable representing the potential amount of inoculum. Based on the accelerated failure time model, we estimated that for each increase in percent leaf area diseased and in number of rainy days, the time-to-death of grape leaves was accelerated by 2.84 and $0.66 \%$, respectively. The survival analysis also showed that leaves that are less than 5 days old at the time of the first infection are more susceptible, and as leaf age increased by 1 day, the time-to-death of the leaves was decelerated by $2.88 \%$. These findings are in accordance with previous reports on the influence of weather variables or host variables on the severity of grape anthracnose $(4,5,20,21,33)$. This study was conducted in a vineyard with a history of anthracnose, so inoculum was probably not a limiting factor, and fungicides were not applied. Nevertheless, the findings have practical implications for grape anthracnose management, suggesting that practices aimed at reducing disease pressure early in the season should help increase leaf survival.

\section{Acknowledgments}

We are grateful to Daniel Rolland and Réjean Bacon for their technical assistance. This work was financially supported by Agriculture and Agri-Food Canada.

\section{Literature Cited}

1. Allison, P. D. 1995. Survival Analysis Using the SAS System. A Practical Guide. SAS Institute, Cary, NC.

2. Anderson, H. W. 1956. Pages 377-382 in: Diseases of Fruit Crops. McGraw-Hill, New York.

3. Anonymous. 2010. Fruit Production Recommendations - Publication 360 2008-2009. Ontario Ministry of Agriculture, Food and Rural Affairs.

4. Brook, P. J. 1973. Epidemiology of grapevine anthracnose, caused by Elsinoe ampelina. N.Z. J. Agric. Res. 16:333-342.

5. Brook, P. J. 1992. Epidemiology of grapevine anthracnose and downy mildew in an Auckland, New Zealand vineyard. N.Z. J. Crop Hortic. Sci. 20:37-49

6. Carisse, O. 2005. Outbreak of anthracnose caused by Elsinoe ampelina in vineyards in Quebec. (Abstr.) American Phytopathological Society, North Eastern Division.

7. Carisse, O., and Lefebvre, A. 2011. A model to estimate the amount of primary inoculum of Elsinoë ampelina. Plant Dis. 95:1167-1171.

8. Carisse, O., and Lefebvre, A. 2011. Evaluation of northern grape hybrid cultivars for their susceptibility to anthracnose caused by Elsinoe ampelina. Online. Plant Health Progress doi:10.1094/PHP-2011-0805-01-RS.

9. Chap, T. L. E. 1997. Applied Survival Analysis. John Wiley and Sons, New York.

10. Collett, D. 2003. Modelling Survival Data in Medical Research, 2nd ed. Chapman and Hall/CRC, Boca Raton, FL.

11. Cox, D. R. 1972. Regression models and life tables (with discussion). J. R. Stat. Soc. B34:187-220.

12. Cox, D. R., and Oakes, D. 1984. Analysis of Survival Data. Chapman and Hall, London.

13. Du Plessis, S. J. 1940. Anthracnose of vines and its control in South Africa. Department of Agriculture, South Africa, Sci. Bull. No. 216.

14. Eichhorn, K. W., and Lorenz, D. H. 1977. Phänologische Entwicklungsstadien der Rebe. Nachrichtenbl. Dtsch. Pflanzenschutzdienstes (Braun-

Table 3. Parameter estimates and test statistics for an accelerated failure time model with the Weibull distribution describing time to defoliation of individual grape leaves (cv. Vandal-Cliche) in Frelighsburg, Quebec, Canada in 2006 to 2008

\begin{tabular}{|c|c|c|c|c|c|}
\hline Parameter & df & Estimate & Standard error & Chi-square & $P>$ chi-square \\
\hline Intercept $\left(\beta_{0}\right)$ & 1 & 4.7864 & 0.0396 & $14,636.70$ & $<0.0001$ \\
\hline $\operatorname{PLAD}_{\text {leaf }}\left(\beta_{1}\right)$ & 1 & -0.0288 & 0.0018 & 267.69 & $<0.0001$ \\
\hline $\operatorname{PLAD}_{\text {shoot }}\left(\beta_{2}\right)$ & 1 & -0.0103 & 0.0021 & 24.82 & $<0.0001$ \\
\hline $\operatorname{LAGE}_{\mathrm{I}}\left(\beta_{3}\right)$ & 1 & 0.0284 & 0.0101 & 7.90 & $<0.0049$ \\
\hline $\operatorname{RAIN}_{\text {dur }}\left(\beta_{4}\right)$ & 1 & -0.0066 & 0.0008 & 60.92 & $<0.0001$ \\
\hline Shape parameter & 1 & 0.4720 & 0.0153 & & \\
\hline Scale parameter & 1 & 2.1188 & 0.0685 & & \\
\hline
\end{tabular}


schweig) 29:119-120.

15. Emmett, R. W., Creecy, H., and Blanch, E. 1981. Fungicide evaluation for control of grapevine black spot or anthracnose. Fungic. Nematicide Tests 36:40.

16. Fox, G. A. 1993. Failure-time analysis: Emergence, flowering, survivorship, and other waiting times. Pages 253-289 in: Design and Analysis of Ecological Experiments. S. H. Scheiner and J. Gurevitch, eds. Chapman and Hall, New York.

17. Hopkins, D. L. 1973. Fungicidal control of bunch grape diseases in Florida. Proc. Fla. State Hortic. Soc. 86:329-333.

18. Hopkins, D. L., and Harris, J. W. 2000. A greenhouse method for screening grapevine seedlings for resistance to anthracnose. HortScience 35:89-91.

19. Kleinbaum, D. G. 1996. Survival Analysis, A Self-Learning Text. SpringerVerlag, New York.

20. Magarey, R. D., Coffey, B. E., and Emmett, R. W. 1993. Anthracnose of grapevines, a review. Plant Prot. Q. 8:106-110.

21. Mirica, I. I. 1988. Anthracnose. Pages 18-19 in: Compendium of Grape Diseases. R. C. Pearson and A. C. Goheen, eds. American Phytopathological Society, St. Paul, MN.

22. Ozoe, S., Takuda, T., and Hirsawa, T. 1972. Studies on the ecology and control of black rot of grapevines. Bulletin of the Shimane Agricultural University. Rev. Plant Pathol. 55:356.

23. Pearson, R. C., and Goheen, A. C. 1988. Compendium of Grape Diseases. American Phytopathological Society, St. Paul, MN.

24. Plocher, T. A., and Parke, R. J. 2001. Northern Winework: Growing grapes and making wine in cold climates. Northern Winework Inc., Hugo, MN.

25. Poni, S., Casalini, L., Bernizzoni, F., Civardi, S., and Intrieri, C. 2006. Effects of early defoliation on shoot photosynthesis, yield components, and grape composition. Am. J. Enol. Vitic. 57:397-407.

26. Sabbatini, P., and Howell, G. S. 2010. Effects of early defoliation on yield, fruit composition, and harvest season cluster rot complex of grapevines. HortScience 45:1804-1808.

27. Scherm, H., and Ojiambo, P. S. 2004. Applications of survival analysis in botanical epidemiology. Phytopathology 94:1022-1026.

28. Sharma, I. M., and Bhardwaj, S. S. 2003. Efficacy and economics of different fungicide spray schedules in controlling premature defoliation disease in apple. Plant Dis. Res. 18:21-24.

29. Shear, C. L. 1929. The life history of Sphaceloma ampelinum de Bary. Phytopathology 19:673-679.

30. Sokal, R. R., and Rohlf, F. J. 1995. Biometry: The Principles and Practices of Statistics in Biological Research, 3rd ed. W.H. Freeman and Company, New York, NY.

31. Steel, R. G. D., Torrie, J. H., and Dickey, D. A. 1997. Principles and Procedures of Statistics: A Biometrical Approach, 3rd ed. McGraw-Hill, Boston, MA.

32. Suhag, L. S., and Grover, R. K. 1972. Overwintering and control of Elsinoe ampelina, the cause of grapevine anthracnose. In: Viticulture in the Tropics. K. Chadha, G. Randhowa, and R. Pal, eds. Horticultural Society of India.

33. Suhag, L. S., and Grover, R. K. 1977. Epidemiology of grapevine anthracnose caused by Sphaceloma ampelinum in north India. Indian Phytopathol. 35:526-528.

34. Thind, S. K., Arora, J. K., Nirmaljitkour, P. K., and Arora, P. K. 2001. Periodicity and prediction model of grape anthracnose in Punjab: An agrometeological approach. Plant Dis. Res. 16:63-67.

35. Thind, S. K., Arora, J. K., Moham, C., and Raj, P. 2004. Epidemiology of powdery mildew, downy mildew and Anthracnose diseases of grapevine. Pages 621-638 in: Diseases of Fruits and Vegetables, Vol. I. Kluwer Academic Publishers, Netherlands.

36. Virk, K., and Grover, R. 1979. Effect of thiophanate-methyl on growth and metabolic activity of Sphaceloma ampelinum. Indian Phytopathol. 32:529533.

37. Williamson, J. G., and Miller, E. P. 2002. Early and mid-fall defoliation reduces flower bud number and yield of southern highbush blueberry. HortTechnology 12:214-216.

38. Zhang, B., and Huang, Y. 1990. A list of important plant diseases in China. Rev. Plant Pathol. 69:97-104. 